\title{
Pulmonary Langerhans' Cell Histiocytosis: A Rare Case of Incipient Radiological Stage
}

\section{Khalid M', Saleemi S ${ }^{2 *}$, Al-Kattan $\mathrm{K}^{3}$, Khoja $\mathrm{H}^{4}$}

${ }^{1}$ Department of Medicine, King Faisal Specialist Hospital, Riyadh, Saudi Arabia ${ }^{2}$ Department of Medicine, King Faisal Specialist Hospital, Riyadh, Saudi Arabia ${ }^{3}$ Department of Surgery, King Faisal Specialist Hospital, Riyadh, Saudi Arabia ${ }^{4}$ Department of Pathology, King Faisal Specialist Hospital, Riyadh, Saudi Arabia

\begin{abstract}
Pulmonary Langerhans' Cell Histiocytosis (PLCH) is a rare interstitial lung disease with characteristic radiological features on high resolution computed tomography (HRCT). The diagnosis is usually delayed as the illness is either asymptomatic or has mild symptoms in the initial stage. We present a case of $54 \mathrm{yrs}$ old smoker who presented with acute febrile illness associated with cough and sputum production due to upper respiratory tract infection. A subtle abnormality on chest X-ray led to the performance of HRCT chest showing few tiny nodules which progressed on repeat HRCT after a period of observation. A thoracoscopic lung biopsy confirmed the diagnosis of Pulmonary Langerhans' Cell Histiocytosis (PLCH). This case represents an earliest radiological stage of PLCH.
\end{abstract}

Keywords: Pulmonary; Langerhans' cell; Histiocytosis; Tomogram; Nodule

\section{Case Report}

A 54 years old male with 30 pack years of smoking history was admitted through the emergency room with acute symptoms of fever, cough and mild shortness of breath. His past history included hypertension, diabetes mellitus and coronary artery disease requiring coronary artery bypass graft. He denied any recent history of weight loss, night sweats, and close contact with a sick patient or travel to a tropical country. On clinical examination, he was febrile and has mild tachycardia and tachypnea. He had normal oxygen saturation and blood pressure, his upper airway examination was unremarkable, examination of chest revealed vesicular breath sounds with no added sounds. Examination of cardiovascular, abdomen and central nervous system was normal. Initial investigation showed a white blood cell count of 16,000 with $81 \%$ neutrophils. His serum C-reactive protein was elevated at $95 \mathrm{mg} / \mathrm{L}$ and ESR was 46 . Serum hepatic and renal profiles were within normal range. A sputum and blood cultures were negative. A presumptive diagnosis of acute viral upper respiratory tract

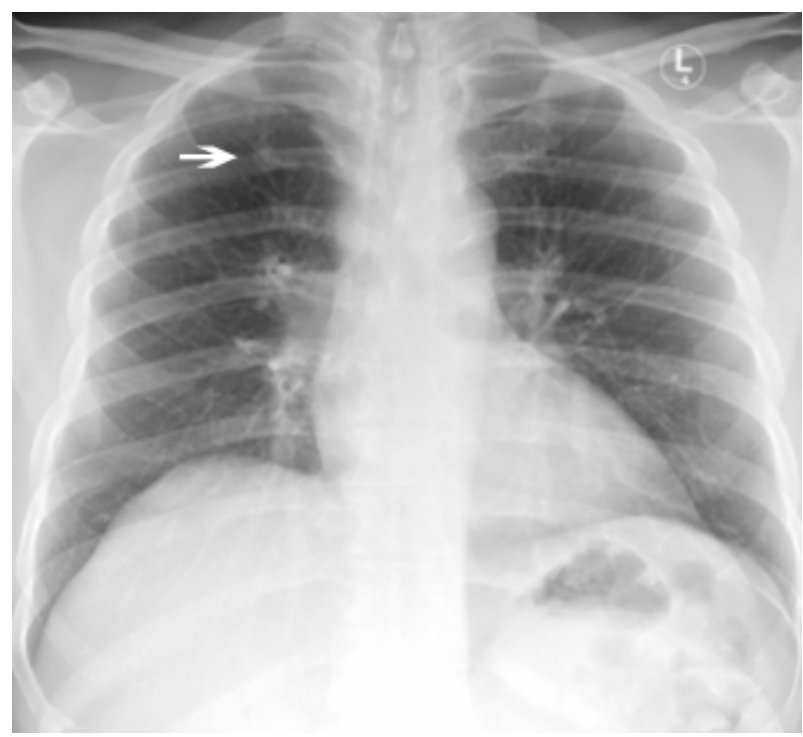

Figure 1: A subtle nodular density in the right upper lobe (arrow). with superadded bacterial infection was made and patient was treated with a course of antibiotics resulting in resolution of all presenting symptoms. Chest X-ray which was done to rule out pneumonia showed a subtle nodular opacity at the right upper lobe (Figure 1). In view of history of prolonged smoking, a high resolution CT scan (HRCT) of the chest was performed to rule out mass lesion. The HRCT chest showed tiny scattered nodules with some showing cavitations and small mediastinal lymph nodes. In addition a hypodense left thyroid nodule was noted (Figure 2). A differential diagnosis of metastatic lesions, fungal infection, Wagener's granulomatosis and septic emboli was suggested. A fine needle aspiration of left thyroid nodule did not show any evidence of malignancy. Tumor markers, fungal serology and vasculitis workup was negative. An echocardiography did not show any evidence of valvular heart disease or vegetations. A fluorodexyglucose positive emission tomogram (FDG-PET) of whole body was performed to rule out underlying malignancy and it did not show any abnormal FDG uptake in the body (Figure 3). After a negative workup for possible causes of multiple nodular lung lesions, it was decided to repeat chest imaging in three to four weeks time. An HRCT chest on follow up showed significant increase in number of cavitating and noncavitating nodules in both lung fileds (Figure 4). The patient denied respiratory symptoms and clinical examination was unremarkable. A video assisted thoracoscopic lung biopsy was performed to establish the diagnosis. Histological examination confirmed the diagnosis of Pulmonary Langerhans' Cell Histiocytosis (PLCH) (Figure 5-7). The patient was advised to abstain from both active and passive smoking and avoid all kinds of smoke exposure. Surprisingly, the repeat HRCT chest two months after cessation of smoking showed almost complete resolution of all nodular densities (Figure 8). The patient was reassured and advised to avoid all types of smoke exposure in future.

*Corresponding author: Saleemi S, MBC 46, Department of Medicine, King Faisal Specialist Hospital and Research Center, P O Box 3354, Riyadh 11211 Saudi Arabia, E-mail: ssaleemi@kfshrc.edu.sa

Received November 10, 2011; Accepted January 28, 2012; Published January 28, 2012

Citation: Khalid M, Saleemi S, Al-Kattan K, Khoja H (2012) Pulmonary Langerhans Cell Histiocytosis: A Rare Case of Incipient Radiological Stage. J Pulmonar Respirat Med 2:114. doi:10.4172/2161-105X.1000114

Copyright: $\odot 2012$ Khalid M, et al. This is an open-access article distributed under the terms of the Creative Commons Attribution License, which permits unrestricted use, distribution, and reproduction in any medium, provided the original author and source are credited. 
Citation: Khalid M, Saleemi S, Al-Kattan K, Khoja H (2012) Pulmonary Langerhans' Cell Histiocytosis: A Rare Case of Incipient Radiological Stage. J Pulmonar Respirat Med 2:114. doi:10.4172/2161-105X.1000114

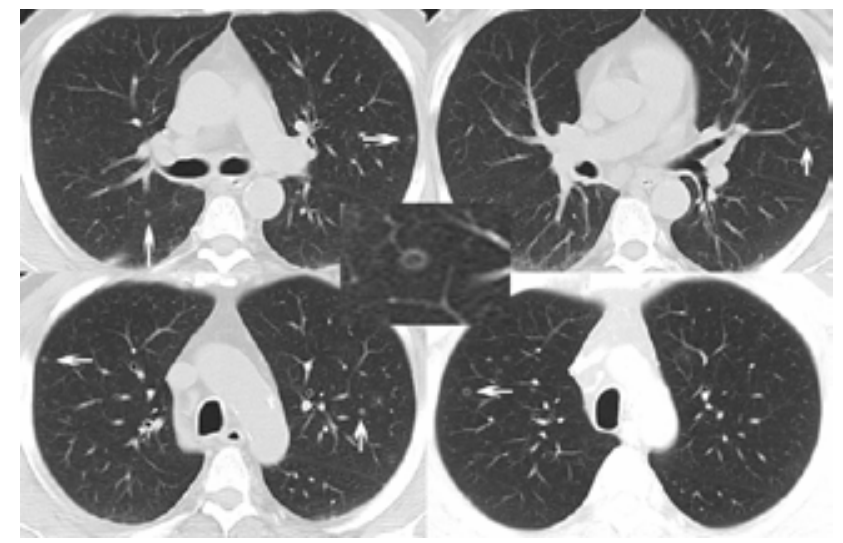

Figure 2: HRCT chest (May 9, 2009) showing multiple tiny nodules (arrows) and a close up view of cavitary.

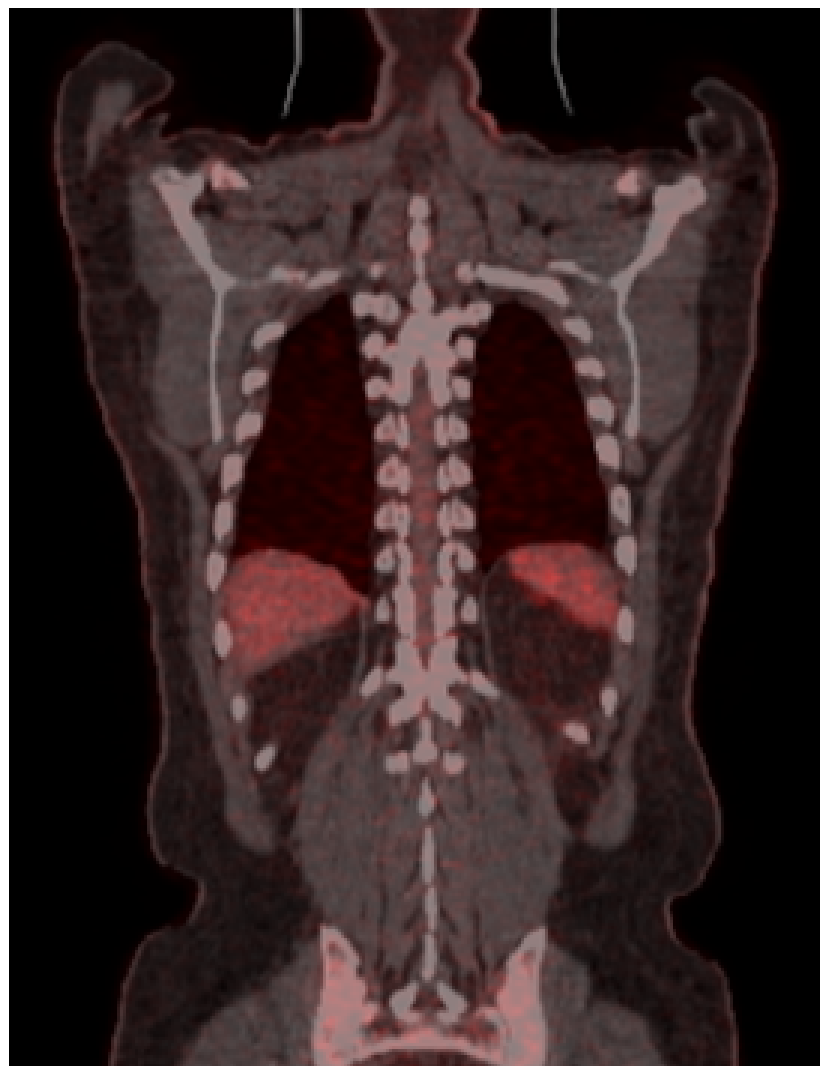

Figure 3: FDG-PET scan of whole body showing no abnormal FDG uptake.

\section{Discussion}

Pulmonary Langerhans' Cell Histiocytosis (PLCH) is an uncommon interstitial lung disease that occurs predominantly in adult cigarette smokers. The term "pulmonary Langerhans' cell histiocytosis" was first described by Farinacci in 1951 and refers to disease in adults that affects the lungs, either in isolation or in addition to other organ systems [1]. PLCH is one of Langerhans' cell histiocytosis (LCH) diseases that are characterized by uncontrolled proliferation and infiltration of various organs by Langerhan's cells varying widely from diffuse body involvement with a very poor prognosis to a localized disease involving only one organ. Several organ systems may be involved in $\mathrm{LCH}$, including the lungs, bone, skin, pituitary gland, liver, lymph nodes, and thyroid [2,3]. Dating back to the era when the disease pathophysiology had been completely unknown, the original term histiocytosis X encompassed three different clinical forms of Langerhans' cell histiocytosis, AbtLetterer-Siwe disease (organomegaly, lymphadenopathy, and skin rash), Hand-Schuller-Christian disease (exophthalmos, diabetes insipidus and osteolysis of the skull) and Eosinophilic Granuloma (isolated osteolytic

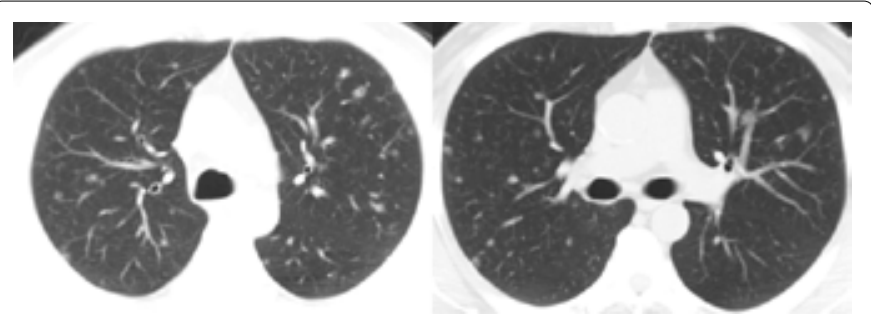

Figure 4: HRCT chest (May 26, 2009) showing multiple bilateral nodules.

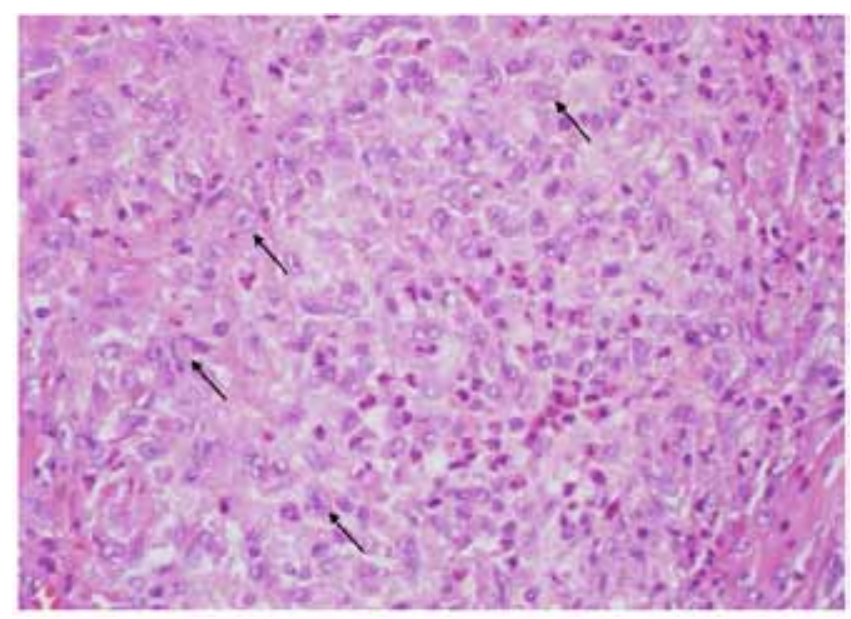

Figure 5: High-power view demonstrating langerhans' cell histiocytes with pale cytoplasm and characteristic nuclear grooves and folds.

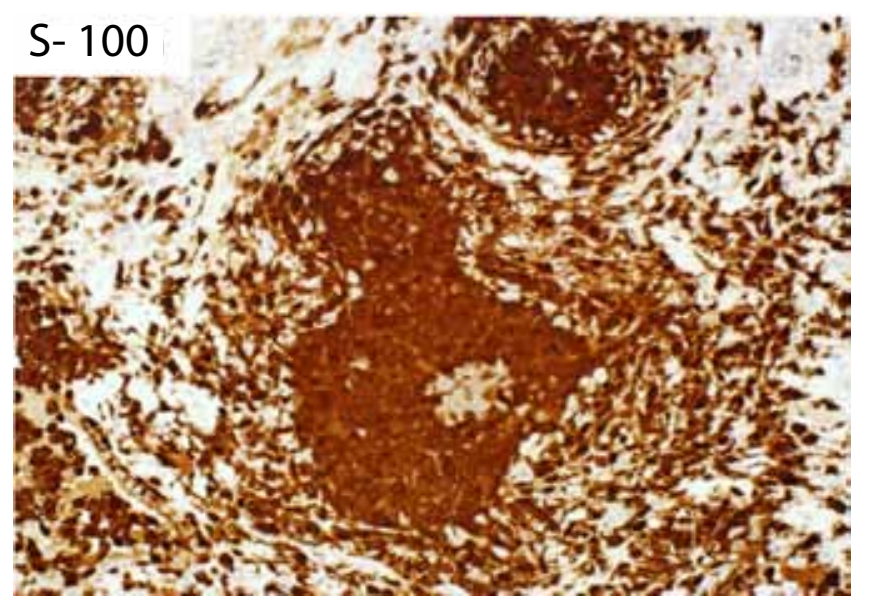

Figure 6: Immunohistochemistry for S-100 demonstrates diffuse staining of Langerhans' cell histiocytes. 


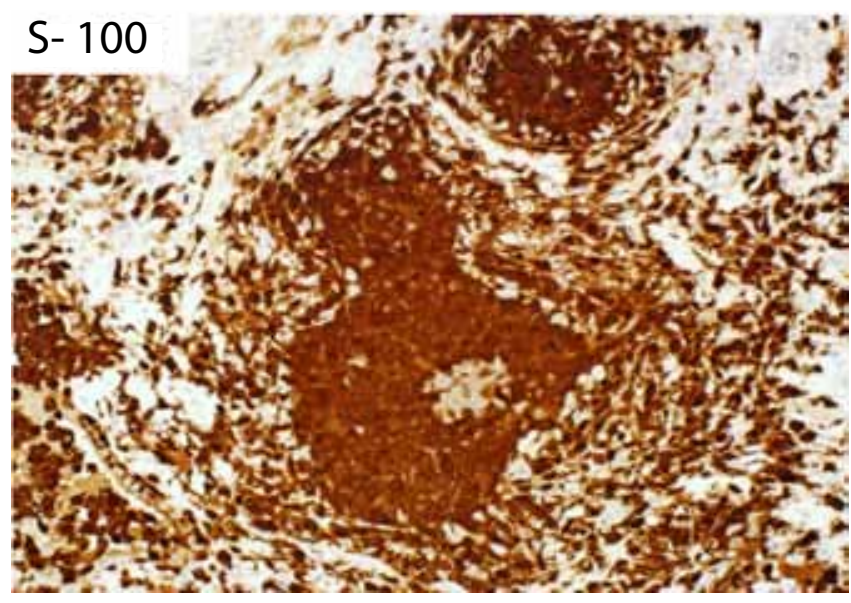

Figure 7: Immunohistochemistry for CD1a demonstrates staining of Langerhans' cell histiocytes.

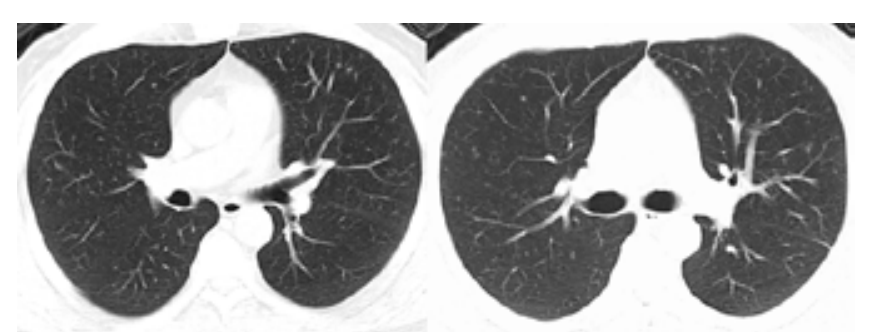

Figure 8: HRCT chest 2 months after smoking cessation showing almost complete resolution of lung nodules with residual tiny cysts.

bone lesions) [4]. The Histiocyte Society has established a simplified classification system. According to this system, PLCH is a disease in adults that affects the lungs, either in isolation or in addition to other organ systems [5]. The peak age of incidence of PLCH is between 20 and 40 years of age. Gender difference varies widely in various studies. Some case series citing male predominance while others describe an equal male to female ratio [6,7]. The etiology of PLCH is not clearly understood, but it is postulated that immune system interactions between Langerhans' cells, pulmonary epithelial cells and lymphocytes may be a cause of interstitial and nodular involvement of lung [8]. The only consistent epidemiologic association is cigarette smoking, which is present in the overwhelming majority (> 90\%) of cases of PLCH. The strong association between smoking history and development of PLCH is well cited although smoking is not related to severity of pulmonary involvement since peak incidence of disease is in relatively young adults. Smoking effects the bronchial epithelial cells releasing several cytokines which can influence proliferation, differentiation and survival of Langerhans' cells leading to their accumulation in the lung parenchyma resulting in lung damage $[9,10]$. Several hypotheses have been proposed to explain the association between cigarette smoking and PLCH. According to one, cigarette smoke induces the secretion of bombesin-like peptides from neuroendocrine cells in the lungs. These peptides may have an important role in mediating lung injury and consequently induce lung fibrosis [11]. Other components of cigarette smoke, such as tobacco glycoprotein, have also been implicated in the pathogenesis of PLCH .Tobacco glycoprotein is an immunostimulant that induces lymphocyte differentiation and lymphokine production [12]. Nevertheless, PLCH occurs in a very small percentage of smokers, so genetic or environmental factors likely contribute to the development of this disease. Other than smoking, lymphoma has been reported to be an associated factor in some case reports $[13,14]$. The most common symptom in patients with PLCH is cough, occurring in almost two thirds of patients. Cough is mostly dry and may be associated with exertional dyspnea, fever, fatigue and weight loss [15]. Chest pain in some patients may be due to rib involvement or more commonly due to pneumothorax which occurs in $10-20 \%$ of patients. Clinical examination is usually unremarkable except in patients with pneumothorax or advanced disease [16]. Chest radiograph findings depend on stage of the disease. In early stage it may show tiny bilateral nodules mainly involving the upper lobes while in advanced stage a reticulonodular pattern with preserved lung volume or even emphysematous change may be evident [17-19]. HRCT of the chest is an excellent tool in predicting the diagnosis of PLCH. Features of diffuse, irregularly shaped cystic spaces with small peribronchiolar nodular opacities predominantly in the upper lobes, is highly suggestive of PLCH [19]. The HRCT chest findings depend on the stage of the disease. In the early stage, the most common finding is nodular change, whereas in the later stages, cystic change and fibrosis predominate. The cysts in PLCH are usually small and thin walled. Although HRCT may show a pathognomonic finding of nodules and cysts, it cannot be used solely to conclude a diagnosis of PLCH. There should be some other evidence of PLCH - either presence of a histologically verified $\mathrm{LCH}$ at a different location or an increased count of CD1a elements in the Bronchoalveolar lavage to determine the diagnoses indirectly. Only lung biopsy gives direct information about presence or absence of typical LCH granuloma [20].

Gallium scan in PLCH is usually negative while FDG-PET scan may be associated with abnormal thoracic and extrathoracic results. Patients with nodular disease are more likely to have abnormal PET scan finding. Although PET scan imaging cannot reliably distinguish between the benign inflammatory nodular lesions of PLCH and malignant lesions yet PET imaging can be used as a screening method in case of a multisystem disease with pulmonary involvement and in the follow up of patients for treatment response [21,22]. Pulmonary function test (PFT) results are variable and may show restrictive, obstructive or mixed defect. Typical findings on PFT include reduced forced vital capacity, normal or increased residual volume and increased residual volume to total lung capacity ratio [23]. Bronchoalveolar lavage may be helpful in making a diagnosis in the right clinical scenario when combined with other modalities like CT scan etc. The diagnostic yield of transbronchial biopsy is generally low because of focal nature of the disease and a thoracoscopic biopsy is needed to establish the diagnosis [24]. The characteristic histological features of PLH are activated Langerhans' cells organized into a loose granuloma and associated with lymphocytes and inflammatory cells, particularly eosinophils and macrophages and positive staining for S-100 protein, CD1a and Lagerin $[25,26]$. Clinical course of patients with PLCH is variable and unpredictable. Spontaneous remission or stable pulmonary status is reported in about half of patients although around $10-20 \%$ of patients may have a progressively declining course leading to end stage lung disease, chronic respiratory failure and cor- pulmonale. There are reports of increased susceptibility to the development of malignant neoplasm in patients with PLCH $[27,28]$. The only effective management in patients with PLCH is cessation of smoking and in advanced stage lung transplant. All other treatment modalities are anecdotal and based on case reports and case series. Although Corticosteroids alone or in combination with cytotoxic agents like Vinblastine, etoposide, 2chlorodeoxyadenosine (2-CdA), and stem cell transplantation, have shown benefit in generalized childhood disease, their use in adult PLCH 
is not recommended [29-34]. The role of steroids in management of PLCH is controversial. In one study corticosteroid use was associated with clinical and radiographic improvement, but no significant change in respiratory function test [2] while in another study it has shown deleterious effect on lung function [6]. In general, a trial of steroids for three to six months is worthwhile in symptomatic patients with nodular disease. Although lung transplant has been performed with success in end-stage PLCH, the risk of recurrence is significant especially in patients who do not quit smoking $[2,35]$.

\section{Conclusion}

In conclusion, PLCH is a rare interstitial lung disease which has strong association with history of cigarette smoking. Most common symptom of this illness is dry cough and pneumothoraces occur in $10-20 \%$ of patients. The disease is suggested by a typical radiological appearance although biopsy is usually required for definitive diagnosis. There is no effective medical therapy and the role of steroids is controversial. Cessation of smoking is the only effective intervention in the management of patients with PLCH. Lung transplant has been done with success in advanced stages of PLCH and there are reports of recurrence of disease in the transplanted lung.

\section{References}

1. Farinacci CJ, Jeffrey HC, Lackey RW (1951) Eosinophilic granuloma of the lung: report of two cases. U S Armed Forces Med J 2: 1085-1093.

2. Schönfeld N, Frank W, Wenig S, Uhrmeister P, Allica E, et al. (1993) Clinical and radiological features, lung function and therapeutic results in pulmonary histiocytosis X. Respiration 60: 38-44.

3. Travis WD, Borok Z, Roum JH, Zhang J, Feuerstein I, et al. (1993) Pulmonary Langernans cell granulomatosis (histiocytosis X). A clinicopathologic study of 48 cases. Am J Surg Pathol 17: 971-986.

4. Lichtenstein $L$ (1953) Histiocytosis $X$; integration of eosinophilic granuloma of bone Letter-Siwe disease and "Schuller-Christian disease" as related manifestations of a single nosologic entity. AMAArch Pathol 56: 84-102.

5. Favara BE, FellerAC, Pauli M, Elaine SJ, Lawrence MW, et al. (1997) Contemporary classification of histiocytic disorders. Med Pediatr Oncol 29: 157-166.

6. Delobbe A, Drieu J, Duhamel A, Wallaert B (1996) Determinants of survival in pulmonary Langerhans' cell granuomatosis (histiocytosis X). Groupe d'Etude en Pathologie Interstitielle de la Société de Pathologie Thoracique du Nord. Eur Respir J 9: 2002-2006.

7. Crausman RS, Jennings CA, Tuder RM, Ackerson LM, Irvin CG, et al. (1996) Pulmonary histiocytosis $X$ : pulmonary function and exercise pathophysiology. Am J Respir Crit Care Med 153: 426-435.

8. Sertl K, Takemura T, Tschachler E, Ferrans VJ, Kaliner MA et al. (1986) Dendritic cells with antigen- presenting capability reside in airway epithelium, lung parenchyma, and visceral pleura. J Exp Med 163: 436-451.

9. Tazi A, Bouchonnet F, Grandsaigne M, Boumsell L, Hance AJ, et al. (1993) Evidence that granulocyte macrophage-colony-stimulating factor regulates the distribution and the differentiation state of dendritic cells/Langerhans cells in human lung and lung cancers. J Clin Inves 91: 566-576.

10. Jung HW, Im JG, Ahn JM (1994) Pulmonary histiocytosis-X: highresolution CT findings correlated with pulmonary function test. J Korean Radiol Soc 30: 299-304.

11. Del Rio M, Hernanz A, de la Fuente M (1994) Bombesin, gastrinreleasing peptide and neuromedin $\mathrm{C}$ modulate murine lymphocyte proliferation through adherent accessory cells and activate protein kinase C. Peptides 15: 15-22.

12. Lemaire I (1991) Bombesin-related peptides modulate interleukin-1 production by alveolar macrophages. Neuropeptides 20: 217-223.

13. Unger JM, England DM, Collins J (1994) Miliary nodules, Hodgkin's disease, and eosinophilic granuloma. J hor Imaging 9: 71-73.

14. Minghini A, Trogdon SD (1998) Recurrent spontaneous pneumothorax in pulmonary histiocytosis X. Am Surg 64: 1040-1042.
15. Howarth DM, Gilchrist GS, Mullan BP, Wiseman GA, Edmonson JH, et al. (1999) Langerhans cell histiocytosis: diagnosis, natural history, management, and outcome. Cancer 15: 2278-2290.

16. Lacronique J, Roth C, Battesti JP, Basset F, Chretien J (1982) Chest radiological features of pulmonary histiocytosis $\mathrm{X}$ : a report based on 50 adult cases. Thorax 37: 104-109.

17. Brambilla E, Fontaine E, Pison CM, Coulomb M, Paramelle B, et al. (1990) Pulmonary histiocytosis $X$ with mediastinal lymph node involvement. Am Rev Respir Dis 142: 1216-1218.

18. Khoor A, Myers JL, Tazelaar HD, Swensen SJ (2001) Pulmonary Langerhans cell histiocytosis presenting as a solitary nodule. Mayo Clin Proc 76: 209-211.

19. Muller NL, Fraser RS, Lee KS, Johkoh T (2003) Diseases of the Lung Radiologic and Pathologic Correlations. 3rd ed. Philadelphia: Lippincott Williams \& Wilkins.

20. Noble RH, Williams AJ (1982) Multiple cavitating pulmonary nodules due to eosinophilic granuloma. Clin Notes Respir Dis 21: 10-12.

21. Krajicek BJ, Ryu JH, Hartman TE, Lowe VJ, Vassallo R (2009) Abnormal Fluorodeoxyglucose PET in Pulmonary Langerhans Cell Histiocytosis. Chest 135 1542-1549.

22. Szturz P, Rehák Z, Koukalová R, Adam Z, Krejči M, et al. (2011) Measuring diffuse metabolic activity on FDG-PET/CT: new method for evaluating Langerhans cell histiocytosis activity in pulmonary parenchyma. Nucl Med Biol.

23. Basset F, Corrin B, Spencer H, Lacronique J, Roth C, et al. (1978) Pulmonary histiocytosisX. Am Rev Respir Dis 118: 811-820.

24. Housini I, Tomashefski JF, Cohen A, Crass J, Kleinerman J (1994) Transbronchia biopsy in patients with pulmonary eosinophilic granloma. Comparison with findings on open lung biopsy. Arch Pathol Lab Med 118: 523-530.

25. Hance AJ, Cadranel J, Soler P, et al. (1988) Pulmonary and extrapulmonary Langerhans' cell granu lomatosis (histiocytosisX). Semin Respir Med 9: 349-368.

26. Badra A, Karamouzis MV, Zolota V, Postramas V (2004) A case of multiorgan langerhans cell histiocytosis presented with pneumothorax. Eur J Intern Med 15 467-469.

27. Vassallo R, Ryu JH, Schroeder DR, Decker PA, Limper AH (2002) Clinica outcomes of pulmonary Langerhans'-cell histiocytosis in adults. N Engl J Med 346: 484-490.

28. Vassallo R, Ryu JH, Colby TV, Hartman T, Limper AH (2000) Pulmonary Langerhans'- cell histiocytosis. N Engl J Med 342: 1969-1978.

29. Soler P, Kambouchner M, Valeyre D, Hance AJ (1992) Pulmonary Langerhans' cell granulomatosis. Annu Rev Med 43: 105-115.

30. ten Velde GP, Thunnissen FB, van Engelshoven JM, Wouters EF (1994) A solitary pulmonary nodule due to eosinophilic granuloma. Eur Respir J 7: 1539-1540.

31. Aerni MR, Aubry MC, Myers JL, Vassallo R (2008) Complete remission of nodula pulmonary langerhans cell histiocytosis lesions induced by 2-chlorodeoxyadenosine in a non-smoker. Respir Med 102: 316-319.

32. Arico M, Girschikofsky M, Genereau T, Klersy C, McClain K, et al. (2003) Langerhans cell histiocytosis in adults report from the international registry of the histiocyte society. Eur J Cancer 39: 2341-2348.

33. Baumgartner I, von Hochstetter A, Baumert B, Luetolf U, Follath F (1997) Langerhans' cell histiocytosis in adults. Med Pediatr Oncol 28: 9-14.

34. Gadner H, Grois N, Arico M, Broadbent V, Ceci A, et al. (2001) A randomize trial of treatment for multisystem langerhans cell histiocytosis. J Pediatr 138: 728-734.

35. Etienne B, Bertocchi M, Gamondes JP, Thévenet F, Boudard C, et al. (1998) Relapsing Pulmonary Langerhans Cell Histiocytosis after Lung Transplantation. Am J Respir Crit Care Med 157: 288-291. 